\title{
HOXE COMENZAMOS A FALAR
}

Experiencia expositiva comisariada colectivamente por los alumnos de la $4^{\circ}$ edicion del "Master de Arte, museologia y crítica contemporáneas" de la Universidade de Santiago de Compostela

Pedro de Llano Neira

Universidade de Santiago de Compostela

Bajo este título — una frase abierta extraída de las protestas del pasado mes de marzo en la plaza de los Aliados de Oporto- el artista portugués André Guedes presentó una exposición en la sala artesonada y en la capilla del colegio de Fonseca de la Universidad de Santiago de Compostela.

Esta exposición formó parte de las actividades académicas de la cuarta edición del máster en Arte, Museología y Crítica Contemporáneas de la USC. Se trata de un proyecto expositivo que mezcla teatro y artes plásticas y que se desarrolló a partir del taller de comisariado, dirigido por Agar Ledo, en el que, junto al artista portugués, participaron los propios estudiantes, que actuaron como comisarios. Se trata de una iniciativa que comenzó a diseñarse hace un año, cuando los diecinueve alumnos del máster establecieron un diálogo con el artista, que tuvo como objetivo principal invitar a reflexionar sobre la acción humana (individual) en el momento histórico presente (colectivo).

No era la primera vez que André Guedes trabajaba en Galicia. En 2003 participó en la exposición Otras alternativas: nuevas experiencias visuales en Portugal, en el MARCO de Vigo. En 2006, en el contexto del proyecto La ciudad interpretada, investigó sobre la figura de Eugenio Montero Rios, con la devolución de la estatua del político que ahora se encuentra en la plaza de Mazarelos, a su emplazamiento original en el centro de la plaza del Obradoiro. El trabajo de este autor se caracteriza por una rigurosa investigación sobre el terreno, en muchas ocasiones relacionada con temas históricos, y

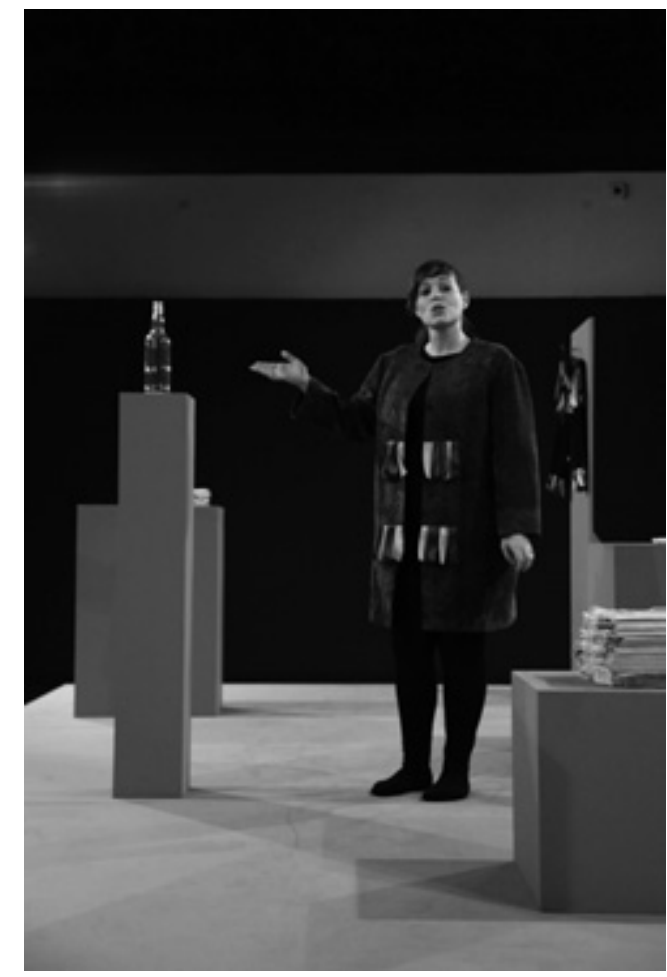

suele implicar la colaboración de diversos colectivos o personas. Además, la práctica de Guedes se define cada vez más por un acusado interés por el mundo del teatro, su historia y los posibles cruzamientos de esta disciplina con las artes plásticas. 

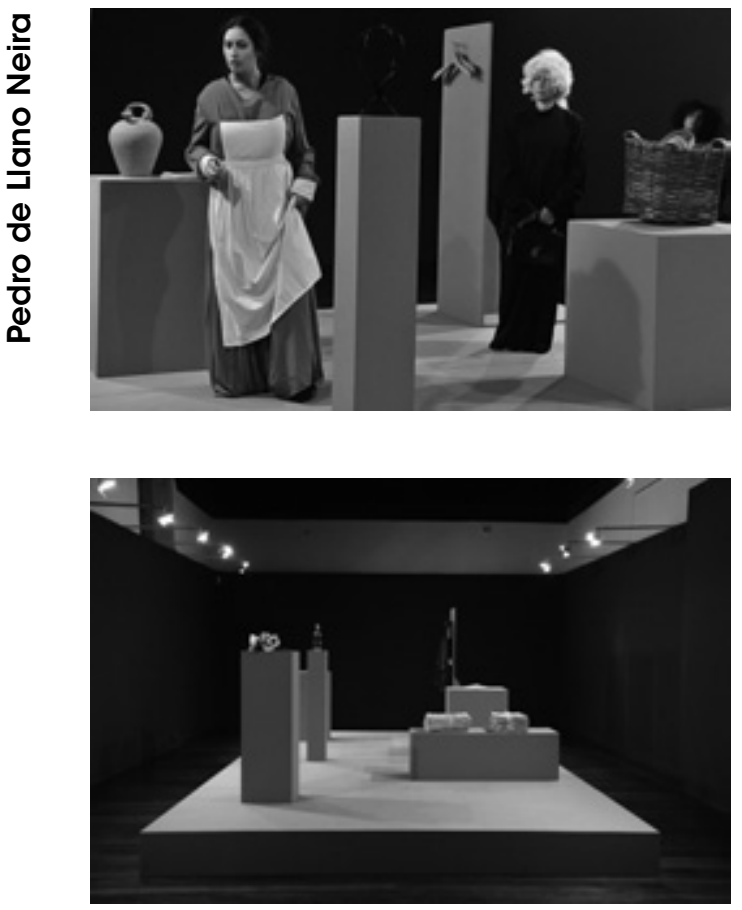

Junto a él, los alumnos del máster intervinieron en este atractivo proceso de trabajo desde sus primeros momentos. Llevaron a cabo tareas de investigación que, después de varios tanteos iniciales, desembocaron en un estudio del espacio expositivo de Fonseca y de su historia como antiguo refectorio tradicionalmente vinculado a la oralidad. De hecho un púlpito preside aún hoy este hermoso espacio renacentista. Este enfoque fue paralelo a un debate sobre los acontecimientos que tuvieron lugar en la primavera de 2011, cuando numerosos colectivos sociales se echaron a la calle en distintas ciudades españolas y portuguesas para protestar por la presente situación de crisis económica y descrédito político que vive Europa.

Esta idea se tradujo en la exposición bajo dos aspectos. Por un lado, el diseño de una escenografía con objetos y figurines procedentes del aula de teatro de la USC. Y, por otro, la teatralización de los textos puestos en escena por actores pertenecientes a los grupos de teatro universitario que incorporaron en sus recita- dos, esos objetos. El discurso teatral es sustituido, en esta ocasión por varios monólogos, escogidos por los comisarios, como respuesta a la petición del artista: al pedir a cada uno de ellos que pensase en un texto resumen de sus preocupaciones, Guedes hace un ejercio consistente en reforzar la importancia de la voz individual. Así las piezas de escritores y filósofos como Voltaire, Marinetti o Picabia. Extractos del Tratado de la tolerancia de Voltaire, el Primer manifiesto político de Marinetti o el Manifiesto caníbal Dadá de Francis Picabia, fueron algunos de los pasajes seleccionados entre el artista y los alumnos. Estas lecturas abordan temas relativos a la moral, al individuo y a los valores en los que nos sentimos reflejados. A pesar de su aparente anacronismo, los antiguos escritos son actualizados en la representación a viva voz de los actores y recobraron toda su actualidad al tratar problemas que todavía hoy siguen vigentes.

La exposición se reparte así entre una presentación formal, compuesta por las tarimas, peanas y elementos de atrezzo y otra más efímera que se corresponde con los momentos en los que los intérpretes recitan los textos elegidos, haciendo uso de los distintos objetos que se muestran. Guedes ensayó este planteamiento en otros proyectos anteriores también de carácter performativo y basados en la transmisión de la palabra, con un empleo que forma parte de las tendencias que actualmente están renovando dichas prácticas. Al autor no le preocupa tanto transmitir un mensaje al espectador como convertir esas lecturas en espejos donde cada persona pueda ver algo distinto. A Guedes le interesa también recuperar la facultad del teatro como importante medio de crítica social. La voz de los "indignados" ya no está en las calles pero esta exposición nos hizo sentir su influencia, haciéndose eco de su filosofía y volviendo a situar a la palabra en el centro de la escena.

Hoxe comenzamos a falar, resultó un proyecto altamente interesante al trabajar conjuntamente en una iniciativa que se aleja de los formatos más habituales y supone nuevos retos para los jóvenes comisarios que se están formando en el máster de Arte, Museología y Crítica Contemporánea, de la Universidad de Santiago de Compostela. 